\title{
Revisão das produções científicas sobre altas habilidades/superdotação no Brasil no período de 2011 a 2015
}

\author{
Mariana de Freitas Pereira Pederro* \\ Denise Rocha Belfort Arantes Brero** \\ Raissa Viviani Silva*** \\ Angélica Maria Teodoro Cunha**** \\ Lucas Faria Gonçalves**** \\ Érico Bruno Viana Campos****** \\ Carmen Maria Bueno Neme
}

\section{Resumo}

Estudos sobre Altas Habilidades/Superdotação são relativamente recentes no Brasil e foram impulsionados a partir da implantação dos NAAH/S e do aumento do número de alunos identificados pelo Censo Escolar. Este crescimento, apesar de importante, ainda é pouco significativo, e reflete as dificuldades para identificar e atender a essa populaçáo. O presente estudo se configura como uma pesquisa de revisão de literatura, que objetiva demonstrar os avanços na área das Altas Habilidades/ Superdotação nos últimos cinco anos. O levantamento realizado nas bases de dados resultou em um total de 52 produçóes, distribuídas entre as seguintes categorias: Políticas públicas e inclusão, Educação e Prática do Professor, Características e identificação, Desenvolvimento de Habilidades, Revisão de literatura, Terminologia e Testes. Concluiu-se que é necessário realizar mais estudos de intervenção, pois grande parte dos artigos baseia-se em estudos teóricos. As intervençóes devem considerar as especificidades da população atendida bem como sua cultura, dessa forma, poderão ser construídas propostas de identificação e atendimento adequadas à realidade brasileira.

Palavras-chave: Educação Especial; Revisão de literatura; Superdotação.

\footnotetext{
* Mestranda em Psicologia pela Universidade Estadual Paulista Júlio de Mesquita Filho, Bauru, São Paulo, Brasil.

** Doutoranda em Psicologia pela Universidade Estadual Paulista Júlio de Mesquita Filho, Bauru, Sáo Paulo, Brasil.

*** Mestranda em Psicologia pela Universidade Estadual Paulista Júlio de Mesquita Filho, Bauru, São Paulo, Brasil.

**** Mestranda em Psicologia pela Universidade Estadual Paulista Júlio de Mesquita Filho, Bauru, São Paulo, Brasil.

***** Mestrando em Psicologia pela Universidade Estadual Paulista Júlio de Mesquita Filho, Bauru, São Paulo, Brasil.

****** Professor doutor da Universidade Estadual Paulista Júlio de Mesquita Filho, Bauru, São Paulo, Brasil.

******* Livre Docente em Psicologia Clínica pela Universidade Estadual Paulista Júlio de Mesquita Filho, Bauru, São Paulo, Brasil.
} 


\section{Review on scientific productions for high abilities/ giffedness in Brazil on period 2011 to 2015}

\section{Abstract}

Studies about High Abilities / Giftedness are relatively recent in Brazil and were driven from implementation of NAAH/ $S$ and increasing the number of students identified by school census, which showed 13,308 registered students in 2014. Although it's important, the increasing is still negligible, and reflects the difficulties to identify and serve this population. This study is configured as a literature review of research that aims to demonstrate the advances in the field of high abilities / giftedness in the last five years. The survey conducted in the databases resulted in a total of 52 productions, distributed among the following categories: Public politics and inclusion, Education and Professor Practice, characteristics and identification, skills Development, literature review, terminology and tests. In conclusion, is necessary to do more intervention studies, since most of the articles are based on theoretical studies. Interventions should consider the specificities of the population served and their culture, this way, may be constructed with appropriate proposals to identify and meet the Brazilian reality.

Keywords: Special Education; Literature review; Giftedness.

\section{Introdução}

Estudos sobre Altas Habilidades/Superdotação (AH/SD) no Brasil são relativamente recentes. Os primeiros livros sobre a temática publicados no país, datam da década de 1930 (DELOU, 2007), enquanto que o primeiro seminário nacional sobre superdotados foi realizado pela Universidade de Brasília (UnB) em 1971, iniciando pesquisas e eventos na área (PÉREZ; FREITAS, 2009).

Antes da criação dos Núcleos de Atividades para Altas Habilidades/Superdotação (NAAH/S), em 2005, somente iniciativas isoladas realizavam o atendimento a esta população, como o Centro para o Desenvolvimento do Potencial e Talento (CEDET) e o Programa Objetivo de Incentivo ao Talento (POINT). Após a implantação desta política pública, o aumento significativo do número de pessoas identificadas com AH/SD impulsionou a produção científica sobre o tema no país. Segundo dados do Censo Escolar, em 2005 foram registrados 2.769 alunos e em 2014 foram 13.308 cadastrados, representando um aumento de 480,61\%. Este crescimento ainda é pouco significativo, dada a incidência de pessoas com AH/SD apontada na literatura, cerca de $3 \%$ a $5 \%$ do total da população, o que representaria cerca de 6 milhôes de brasileiros (PÉREZ, 2003). As dificuldades para descrever e identificar esta população, somadas às crenças e mitos que a envolve, são barreiras significativas no processo de cadastramento de pessoas com $\mathrm{AH} / \mathrm{SD}$ em programas especializados (FREITAS; BARBOSA, 2011; OLIVEIRA; ANACHE, 2011; PASSOS; BARBOSA, 2011; GUENTHER; RONDINI, 2012; CARDOSO; BECKER, 2014; TENTES; FLEITH, 2014; VIEIRA, 2014; ALENCAR, 2015). 
De acordo com a Política Nacional de Educação Especial na Perspectiva da Educação Inclusiva (2008):

Alunos com AH/SD demonstram potencial elevado em qualquer uma das seguintes áreas, isoladas ou combinadas: intelectual, acadêmica, liderança, psicomotricidade e artes. Também apresentam elevada criatividade, grande envolvimento na aprendizagem e realizaçâo de tarefas em áreas de seu interesse. (BRASIL, 2008, p. 15).

Outra característica que define esta população é a assincronia, descrita como o desenvolvimento psicomotor, intelectual, afetivo e cronológico não linear, que traz ao indivíduo uma intensa sensação de descompasso na sua relaçâo com o mundo (OUROFINO; GUIMARÃES, 2007). Segundo Fleith e Alencar (2007, p. 45), esses indivíduos demonstram uma "disparidade entre seu desenvolvimento cognitivo e maturidade física ou emocional”.

Quanto às crenças e mitos, Fleith (2006) descreve que muitos acreditam que as pessoas com $\mathrm{AH} / \mathrm{SD}$ possuem recursos próprios para crescerem e desenvolverem seus talentos, que terão bom desempenho em todas as áreas do conhecimento, que apresentam algum tipo de distúrbio ou disfunção ou que são imunes a qualquer problema emocional, que a identificação deva ser mantida em segredo para a família, entre outras crenças que, oriundas da falta de informaçáo e de preconceitos, frequentemente impedem sua identificação, impossibilitando seu acesso às oportunidades de crescimento e desenvolvimento.

Analisando as revisóes de literatura realizadas até o ano de 2011, foram encontrados dois artigos. Nakano e Siqueira (2012) realizaram um levantamento das publicaçôes brasileiras sobre superdotação entre os anos de 2002 e 2009 e encontraram 19 artigos que abordam os seguintes temas : definiçóes conceituais, modelos e formas de identificação, modelos de atendimento e programas de enriquecimento, leis brasileiras que norteiam a atuação de diferentes profissionais junto a esse público específico, pesquisas com professores, famílias e o ambiente escolar, estudos sobre a dimensão sócio-emocional e por fim, as desordens comportamentais e emocionais vinculadas à superdotação. Concluiu-se que há um interesse recente pela temática, justificando algumas dificuldades que ainda são notadas, tais como divergências na definição do conceito e a falta de instrumentos específicos validados e normatizados. Trabalhando com teses e dissertaçôes brasileiras sobre AH/SD, Chacon e Martins (2014) realizaram um levantamento que demonstrou o crescimento de pesquisas sobre esse tema com predomínio de publicaçôes na área da Educação.

Diante disso, esse estudo tem como objetivo analisar as publicaçóes brasileiras sobre AH/SD nos últimos 5 anos (2011 a 2015), a fim de caracterizar os principais assuntos debatidos e os avanços teóricos e práticos nesse período.

\section{Método}

Este estudo se configura como uma pesquisa de revisáo de literatura (GIL, 2002). Foi realizado o levantamento dos artigos científicos publicados em periódicos brasileiros, utilizando as bases de dados Scielo, Portal da Capes, BVS, Bireme e Par- 
thenon e os descritores "Altas Habilidades", "Superdotação", "Dotação" e "Talento". O período contemplado foi de 2011 a 2015. Nos critérios de exclusão constavam artigos internacionais, artigos nacionais não publicados no período definido, dissertaçôes, teses e outros tipos de produção científica que não abordavam especificamente a temática. Com isso chegou-se a um total de 52 artigos. Posteriormente, foram lidos os resumos dos artigos selecionados e categorizados por assunto.

Visto que os alunos com AH/SD são integrantes da Educação Especial, a primeira categoria trata das políticas públicas voltadas a esta população, enquanto que na segunda, denominada "Educação e prática do professor", encontram-se as publicaçóes que abrangem as especificidades deste trabalho. A terceira trata da identificação da pessoa com AH/SD e sua caracterização, trabalho essencial para que ela seja direcionada a programas específicos. Na quarta categoria deste artigo, será abordado o tema "Desenvolvimento de Habilidades". Estudos de revisão de literatura foram agrupados na quinta categoria e, na sexta, encontram-se as publicaçóes sobre terminologia, essenciais para a comunicação efetiva entre os diferentes profissionais que trabalham com esta temática. Na sétima categoria se encontram as publicaçóes sobre avaliaçốes e testes utilizados no trabalho com pessoas com AH/SD.

\section{Resultados}

O levantamento realizado nas bases de dados resultou em um total de 52 produçóes, publicadas em 25 periódicos, principalmente nas áreas de Educação Especial (26 produçóes) e Psicologia (19 produçóes). Também foram encontradas publicaçóes na área de Avaliação Psicológica, Orientação Profissional e em um periódico sobre estudos feministas. A maioria dos trabalhos se concentra na Revista Educação Especial (Santa Maria), com 15 artigos publicados.

\section{Políticas públicas e inclusão}

Três artigos se enquadraram nesta categoria. Jesus e Vieira (2011) analisaram como as legislações nacionais de Educação Especial vêm sendo assumidas pelos municípios do Estado do Espírito Santo, e discutiram as tensóes, os desafios e possibilidades que atravessam esse processo.

O artigo de Batista e Mettrau (2012) trata da inclusão social das pessoas com $\mathrm{AH} / \mathrm{SD}$ e aponta suas características, como o não conformismo e a curiosidade, que dificultam sua adaptação em uma sociedade convencional.

Por fim, Pérez e Freitas (2014) analisaram políticas públicas brasileiras para alunos com AH/SD, apontando a necessidade do reconhecimento e registro no Censo Escolar, bem como a formação de professores e gestores, além do apoio técnico, financeiro e a fiscalização das atividades desenvolvidas pelos NAAH/S. Concluíram que o atendimento educacional especializado é oferecido de forma precária, pois essa demanda ainda náo é aferida corretamente nas escolas devido a preconceitos que impedem a identificação dessas pessoas. 


\section{Educação e prática do professor}

Nesta categoria foram encontrados oito artigos, sendo o público-alvo alunos com AH/SD e professores. Barreto e Mettrau (2011) investigaram as representaçóes dos professores sobre AH/SD e a existência de indicação de alunos com esse perfil para atendimento. Os resultados mostraram que esses professores já tinham ouvido falar sobre o tema e perceberam que, em algum momento da sua trajetória profissional, negaram ter alunos com AH/SD. Buscando avaliar a percepçáo de professores sobre $\mathrm{AH} / \mathrm{SD}$, além da formação desejável para atender esta população, Martins e Alencar (2011) descrevem que os entrevistados consideram como esperada a formação continuada, um currículo de graduação adaptado ao tema e uma pós-graduação na área.

O estudo de Veiga, Grande e Grochoski (2013) objetivou compreender a percepção que os alunos com AH/SD tem de si mesmo, bem como o modo como o professor avalia e trabalha com eles.

Ainda inserido nesta questão da percepçáo dos professores, o estudo de Cianca e Marquezine (2014), realizado com docentes e coordenadores da Universidade Estadual de Londrina, mostrou que estes geralmente se utilizam do senso comum quando se referem à superdotação. Estes resultados tem relação com os encontrados no estudo de Pérez e Freitas (2011), que analisou aspectos que prejudicam o encaminhamento pedagógico dos alunos com AH/SD ou a concretização de seu atendimento, a saber: desinformação, falta de formação acadêmica e docente nessa área e representação cultural dessa população afetada pelos mitos e crenças populares.

Outro artigo analisou os fatores associados ao baixo desempenho de alunos superdotados, denominados underachievement. Os autores chamam a atenção para a importância dos educadores e pais reconhecerem a existência dessa condição em indivíduos com $\mathrm{AH} / \mathrm{SD}$ e os fatores a ela associados, a fim de propor práticas educativas e pedagógicas que atendam as necessidades de cada aluno (OUROFINO; FLEITH; GONÇALVES, 2011).

Concentrando discussóes sobre preconceito e estereótipo em alunos com AH/ SD, Reis e Gomes (2011) investigaram os critérios utilizados para identificar e encaminhar este público a programas especializados. A análise revelou o tratamento distinto por parte dos professores em relação ao gênero, encaminhando um número menor de crianças do sexo feminino.

Por fim, um artigo trabalhou com a temática "bullying", comparando sua ocorrência entre estudantes com e sem características de dotação e talento por meio da aplicação de questionários. Não houve diferenças significativas entre os dois grupos, porém os estudantes com dotação e talento para artes são mais vitimizados do que estudantes com talento para outros domínios. (OLIVEIRA; BARBOSA, 2012). 
Mariana de Freitas Pereira Pederro - Denise Rocha Belfort Arantes Brero - Raissa Viviani

Silva - Angélica Maria Teodoro Cunha - Lucas Faria Gonçalves - Érico Bruno Viana

Campos - Carmen Maria Bueno Neme

\section{Características e identificação}

Essa categoria teve 22 publicaçóes. Em função do grande número de artigos encontrados, foram criadas cinco subcategorias: Revisão de Literatura, Ensaios Teóricos, Estudos de Caso, Estudos de Comparação entre Grupos, Identificação de Pessoas com AH/SD.

\section{- Revisão de Literatura}

Ourofino e Fleith (2011) realizaram uma revisão de literatura sobre superdotados underachievers. Ao final, ressaltam a importância de se considerar aspectos do contexto social desta população, como a escola e a família, além de aspectos do indivíduo.

Freitas e Barbosa (2011) realizaram uma análise cientométrica sobre a autoeficácia e características de dotaçáo e talento. Os resultados apontam para uma fragmentação das publicaçóes ao longo dos anos, um predomínio de estudos realizados com adolescentes e um expressivo número de pesquisas sobre auto eficácia, dotação e talento, no entanto, poucos correlacionam essas variáveis.

Por fim, Lamas e Barbosa (2011) fizeram um levantamento de produçóes sobre interesses profissionais e escolha de indivíduos com dotação e talento, concluindo que as pesquisas encontradas enfatizavam apenas alguns aspectos dos interesses profissionais dessas pessoas.

\section{- Ensaios teóricos}

Quatro ensaios teóricos foram selecionados, como o de Freitas e Stobäus (2011) em que foi discutido um currículo voltado às pessoas com AH/SD, de acordo com a política de inclusão escolar. Já Pérez (2011) realizou uma análise crítica do livro "A cultura dos superdotados?”, de Bergès-Bounes e Calmettes-Jean, para mostrar como os mitos podem ajudar a criar uma imagem distorcida das pessoas com superdotação. A autora conclui afirmando que o atendimento educacional especializado para essa população já é uma realidade, mas que a prática precisa também ser um fato e, para isso, é necessário investir na formação dos professores, gestores, profissionais de saúde, na família e na sociedade.

No terceiro artigo, Rangni e Costa (2012) analisaram o filme "Gênio Indomável”, que trata da história de um jovem com talento matemático. Destacam que o filme é baseado no senso comum, o que pode distorcer a percepção em relação aos indivíduos talentosos, gerando a crença de que são todos "gênios".

Por fim, um trabalho de natureza teórica sobre AH/SD e Síndrome de Asperger buscou identificar características semelhantes e discrepantes entre esses sujeitos por meio da análise de livros, artigos e teses já publicadas. Os resultados apontaram que há mais discrepâncias do que semelhanças entre estes dois temas. (VIEIRA; SIMON, 2012). 


\section{- Estudos de comparação entre grupos}

Comparando um grupo de 21 alunos superdotados com outro composto por 27 não-superdotados, matriculados no $6^{\circ}$ ano de uma escola pública, o estudo de Gonçalves e Fleith (2011) objetivou avaliar os níveis de criatividade e inteligência e a relação entre esses. Porém, não foi encontrada uma relação entre inteligência e criatividade, nem diferenças em relação à inteligência entre os dois grupos. Quanto à criatividade, os superdotados tiveram desempenho superior.

Guenther e Rondini (2012) buscaram compreender o domínio conceitual de professores de nível básico em relação aos alunos dotados e talentosos. Participaram do estudo professores envolvidos na área e professores da rede pública. Ambos os grupos apresentaram conceituação confusa em relação aos termos "superdotação" e "altas habilidades”. Já França-Freitas, Del Prette e Del Prette (2014), objetivaram caracterizar o repertório de habilidades sociais em crianças dotadas e talentosas e identificar semelhanças e diferenças com crianças não dotadas. Os resultados obtidos, através da aplicação de instrumentos, apontam um desempenho melhor em crianças dotadas, exceto nas categorias empáticas.

Por fim, Lamas e Barbosa (2015) compararam estudantes com e sem dotação e talento, em relação aos fatores pessoais e de aprendizagem que podem auxiliar no processo de escolha profissional. Concluiu-se que ambos os grupos poderiam se beneficiar da Orientação Profissional.

- Estudos de Caso

Cinco artigos foram encontrados. O primeiro comparou características de superdotação em irmãos, principalmente em relação à capacidade e criatividade. $\mathrm{O}$ estudo foi realizado com um par de gêmeos monozigóticos de 15 anos de idade e, após extrair informações de um banco de dados já existente e coletar informaçóes por meio de outros instrumentos, verificou-se que a criatividade de ambos é superior, principalmente a verbal (PASSOS; BARBOSA, 2011).

Pérez e Freitas (2012) fizeram um estudo longitudinal, cujos participantes foram duas mulheres de 47 e 50 anos de idade, identificadas AH/SD. Constatou-se que as participantes aceitaram progressivamente sua condição e discutiu-se como a sociedade reprime a expressão do talento na mulher. Já Camargo e Freitas (2013) tiveram como sujeito um menino de 12 anos de idade, com AH/SD e dificuldades de aprendizagem. As entrevistas realizadas com o sujeito e sua professora apontam que, se as expressôes da inteligência dos alunos com AH/SD forem estimuladas em sala de aula, elas podem refletir na qualidade da aprendizagem desses alunos.

Embasado na teoria psicanalítica, o estudo de caso de Miranda e Cohen (2013) conclui que esta abordagem também pode contribuir no atendimento às pessoas com AH/SD..

Alencar (2015) apresenta dois estudos de caso que, segundo a autora, expandiram o conhecimento da área de superdotação. O primeiro, desenvolvido por David Feldman, que chamou a atenção para os aspectos individuais e ambientais mais pró- 
Mariana de Freitas Pereira Pederro - Denise Rocha Belfort Arantes Brero - Raissa Viviani

Silva - Angélica Maria Teodoro Cunha - Lucas Faria Gonçalves - Érico Bruno Viana

Campos - Carmen Maria Bueno Neme

ximos das crianças prodígios que pudessem contribuir para o desenvolvimento do seu potencial. O segundo, realizado por Sally Reis, propôs a teoria do desenvolvimento do talento feminino a partir de uma investigação com 22 mulheres. Essa teoria inclui aspectos como talentos em determinadas áreas, inteligência contextual e habilidade acima da média.

\section{- Identificação de Pessoas com AH/SD}

Foram encontrados 6 artigos publicados. Linhares, Filho e Mettrau (2013) buscaram identificar o perfil dermatoglífico de crianças e adolescentes com AH/SD. Após a análise das impressôes digitais, concluíram que esta ferramenta pode auxiliar na identificação desses indivíduos, já que os desenhos dos dedos das mãos se assemelham com as características dos atletas de alto rendimento.

O estudo de Negrini e Freitas (2013) objetivou identificar alunos surdos com AH/SD e mostrar para os profissionais a necessidade de atendimento diferenciado para essa população. A intervenção realizada possibilitou que estes profissionais adquirissem maior conhecimento a respeito do o tema e sobre a influência do ambiente para o desenvolvimento de habilidades.

Tomando como sujeitos quatro adolescentes em situação de rua e com potencial para AH/SD, Cardoso e Becker (2014) os acompanharam por três meses, em seus ambientes. Realizaram entrevistas semiestruturadas e aplicaram instrumentos, delineando suas potencialidades. Concluiu-se que tal intervenção pôde contribuir para a valorização da cidadania e superação de adversidades.

Tentes e Fleith (2014a) tiveram como objetivo avaliar e identificar a prevalência de baixa performance acadêmica entre alunos que frequentavam o Atendimento Educacional Especializado ao Estudante com AH/SD, além de descrever o perfil dos superdotados e dos superdotados underachievers. Concluíram que há superdotados underachievers entre os estudantes superdotados e a heterogeneidade das características escolares e pessoais é que distingue a superdotaçáo. Em outro estudo, Tentes e Fleith (2014b) investigaram a inteligência, motivação para aprender, autoconceito, criatividade, desempenho escolar e atitudes parentais de estudantes com superdotação e superdotados underachievers. Como resultado, os indivíduos underachievers obtiveram escores superiores em motivaçáo extrínseca. Quanto ao gênero, o desempenho dos meninos foi superior em relação à inteligência e o das meninas em relação ao desempenho escolar, criatividade verbal, autoconceito e motivaçáo intrínseca. Em relação às atitudes parentais, não houve diferença.

O estudo de Vieira (2014) avaliou os alunos participantes do Programa de Educação Tutorial (PET) na Universidade Federal de Santa Maria, a fim de captar indicadores de $\mathrm{AH} / \mathrm{SD}$. A pesquisa foi realizada mediante aplicação de instrumentos, grupos focais e entrevistas individuais. Como resultado, foram encontradas seis alunas e dois alunos com os indicadores. Concluiu-se que os métodos utilizados foram válidos para a identificação dessa população. 


\section{Desenvolvimento de habilidades}

Sete artigos encontrados analisam fatores que influenciam o desenvolvimento de habilidades ou descrevem programas que visam oferecer condiçóes para tal.

Um destes é a tradução do texto "The schoolwide enrichment model: a comprehensive plan for the development of talents and giftedness" de Joseph Renzulli, que discorre sobre o Modelo de Enriquecimento para toda a Escola (SEM). Tal programa, utilizado com estudantes superdotados e talentosos academicamente, poderia ser utilizado para desenvolver os pontos fortes e talentos de todos os educandos, segundo o autor (RENZULLI, 2014).

Já Miranda e Almeida (2011), professores portugueses, descrevem as práticas do Programa Odisseia e alguns resultados, como um melhor desempenho escolar e da criatividade figurativa. No Brasil, Delou (2014) descreve o funcionamento de um programa com base na metodologia da pesquisa-ação, realizado na Universidade Federal Fluminense. Articulando ações de ensino, pesquisa e extensão, este envolve a participação da família e da escola dos envolvidos.

Visando ao desenvolvimento de talentos, Chagas e Fleith (2011) procuraram identificar fatores que influenciam o desenvolvimento de habilidades a partir da percepção de adolescentes talentosos, de seus familiares e professores. Já Prado, Fleith e Gonçalves (2011) abordam o tema do desenvolvimento do talento em uma perspectiva feminina, visto que as mulheres sofrem influência de forças culturais e sociais neste processo que, muitas vezes, tendem a inibí-las.

Ao analisar as características e a dinâmica familiar de adolescentes participantes de um programa de atendimento ao superdotado, Ferreira e Fleith (2012) constataram a relevância do papel da família para o desenvolvimento do talento dos filhos. Por fim, Pfeiffer e Wechsler (2013) apresentam um modelo para estimular a liderança criativa em superdotados, mostrando ser possível identificar a superdotação e desenvolver tal liderança a partir deste processo.

\section{Revisão de publicações sobre AH/SD}

Foram encontrados 6 artigos. No primeiro, Barbosa, Almeida e Mota (2012) analisaram a produção científica sobre o leitor talentoso e constataram que esse tema é pouco pesquisado e quando isso ocorre, o foco recai sobre o atendimento às necessidades educacionais especiais.

Analisando as publicaçóes brasileiras sobre AH/SD entre os anos de 2002 e 2009, Nakano e Siqueira (2012) encontraram 19 artigos abordando diferentes dimensôes do tema e notaram algumas divergências na definição do conceito e a falta de instrumentos específicos validados e normatizados.

Mosquera, Stobäus e Freitas (2013) apresentam uma revisão das principais ideias referentes às AH/SD para compreender a evoluçáo desses conceitos na perspectiva da Abordagem ao Longo da Vida. Os autores aprofundam aspectos do desenvolvimento humano e da personalidade ao longo da vida e sugerem possibilidades de atenção a estas pessoas. 
Mariana de Freitas Pereira Pederro - Denise Rocha Belfort Arantes Brero - Raissa Viviani Silva - Angélica Maria Teodoro Cunha - Lucas Faria Gonçalves - Érico Bruno Viana

Campos - Carmen Maria Bueno Neme

Trabalhando com teses e dissertaçôes brasileiras sobre AH/SD, Chacon e Martins (2014) demonstraram o crescimento de pesquisas sobre esse tema, com predomínio de publicações na área da Educação.

Já Gama (2014) apresenta uma discussão entre dois conceitos de inteligência distintos, porém compatíveis, o de Howard Gardner (Teoria das Inteligências Múltiplas) e o de Robert Sternberg (Teoria Triárquica de Inteligência) e aponta que os diferentes processos definidos por Sternberg podem ser aplicados a cada uma das inteligências de Gardner, não só na identificação de alunos superdotados, como também no desenvolvimento de currículos que oportunizem o desenvolvimento de seus potenciais.

Valle-Ribeiro e Barbosa (2014) procuraram artigos sobre professores de alunos com dotação e talento e encontraram 20 estudos, produção considerada pequena. A maioria deles foi publicada nos Estados Unidos, com predominância de estudos empíricos, tidos como relevantes para a oferta de atendimento educacional adequado para estes alunos.

\section{Terminologia}

Foram encontrados dois artigos referentes a esta categoria, ambos publicados em 2011. No primeiro, Chacon e Paulino (2011), através de uma pesquisa de publicaçóes sobre AH/SD no período de 1966 até 2009, investigam se há necessidade de explicar diferentemente os conceitos precoce, prodígio, gênio e altas habilidades. Os autores concluem que a diferenciação de tais conceitos é necessária, devendo haver um olhar mais aprofundado para a precocidade e os prodígios.

Já Rangni e Costa (2011) fazem um levantamento das publicaçóes brasileiras para discutir as nomenclaturas utilizadas por diversos autores. Identificaram que, além de diferentes usos terminológicos, existem também conflitos quanto aos conceitos, o que pode comprometer o atendimento educacional para estudantes com $\mathrm{AH} /$ SD.

\section{Instrumentos de avaliação}

Foram encontrados quatro artigos. No primeiro, Nakano e Siqueira (2012) investigaram evidências de validade de conteúdo da versão brasileira do instrumento de avaliação internacional Gifted Rating Scales (GRS) (PFEIFFER; JAROSEWICH, 2003). Os resultados apontaram a adequação do instrumento.

Veiga (2014) objetivou avaliar a eficácia da psicopedagogia modular como modelo de identificação de pessoas com AH/SD. Participaram da avaliação 28 alunos de 8 a 17 anos, que foram submetidos a uma bateria de instrumentos, entre eles o WISC-III, questionário para pais, , provas multimodais e cognitivas modulares. Os resultados apontaram que a Psicopedagogia Modular, com seu modelo dinâmico de avaliação, é eficaz para a avaliação de pessoas com AH\SD.

Dois estudos se propuseram a analisar e validar as categorias de uma Bateria para Avaliação das $\mathrm{AH} / \mathrm{SD}$, composta por seis sub testes, sendo quatro de inteligência 
(Raciocínio Verbal, Abstrato, Numérico e Lógico) e dois de criatividade (Completando Figuras e Criação de Metáforas). O primeiro investigou a validade do instrumento e os resultados apontaram sua eficácia (RIBEIRO; NAKANO; PRIMI, 2014). Eles, porém, ressaltam a importância da participação dos professores na identificação dos alunos para um diagnóstico mais preciso. O segundo estudo analisou os 72 itens dos seis sub testes desse instrumento e os resultados apontaram sua adequação, porém, indica a necessidade de revisão de três itens no subteste de raciocínio verbal (NAKANO et al, 2015).

\section{Discussão}

Dos 52 artigos analisados observou-se uma prevalência de estudos teóricos, em comparaçáo com estudos de intervenção. A maioria destes focou nas características e na identificação de pessoa com AH/SD, totalizando 22 publicaçôes, o que sugere que não há consenso sobre as estratégias a serem utilizadas para a identificação desta população. As próprias características que definem uma pessoa com AH/SD ainda não estão claras para grande parte da populaçáo, principalmente para os professores, que deveriam fazer o encaminhamento para serviços especializados. Tal caracterização, segundo diferentes estudos, ainda é permeada por mitos e crenças (RANGINI; COSTA, 2012; CIANCA; MARQUEZINE, 2014; PEREZ; FREITAS, 2014).

Esta dificuldade se acentua quando analisamos a categoria "Terminologia”, em que os dois estudos encontrados concordaram que há conflitos nas definiçôes sobre AH/SD (CHACON; PAULINO, 2011; RANGNI; COSTA, 2011). Rangni e Costa (2011) ressaltam a importância de um cuidado com o uso terminológico das palavras para favorecer a inclusão.

Outro destaque foi o aumento de $273 \%$ de publicaçóes em relaçáo ao levantamento realizado por Nakano e Siqueira (2012), que encontraram 19 artigos. Porém, muitos dos temas ainda se repetem sendo que as novidades são a discussão quanto às questôes de gênero, os instrumentos de avaliação, os superdotados underachievement e estudos com crianças surdas e em situaçáo de rua.

Questôes de gênero foram abordadas em três artigos (PRADO, FLEITH e GONÇALVES, 2011; REIS e GOMES, 2011; PÉREZ e FREITAS, 2012) e estes indicam a necessidade de se pensar em estratégias específicas para a identificação e o atendimento das mulheres. Esta demanda se justifica pelo fato de que, historicamente, as mulheres não tiveram as mesmas oportunidades que os homens para desenvolver e demonstrar o seu talento devido às barreiras culturais, sociais e econômicas. Estas influências tendem a inibir o desenvolvimento do talento na mulher, ou então fazer com que elas mesmas os atribuam ao seu esforço ou à sorte, enquanto que os homens costumam atribuir seus talentos à sua capacidade. Tal preconceito faz com que as mulheres sejam sub-representadas em programas de atendimento ao aluno com $\mathrm{AH} / \mathrm{SD}$, devendo os professores estarem preparados para indicá-las.

Quanto aos instrumentos de avaliação para identificar pessoas com AH/SD, percebe-se uma escassez de estudos, bem como de pesquisadores na área, sendo que três artigos dos quatro encontrados foram publicados pela mesma autora (NAKA- 
Mariana de Freitas Pereira Pederro - Denise Rocha Belfort Arantes Brero - Raissa Viviani

Silva - Angélica Maria Teodoro Cunha - Lucas Faria Gonçalves - Érico Bruno Viana

Campos - Carmen Maria Bueno Neme

NO; SIQUEIRA, 2012; RIBEIRO; NAKANO; PRIMI, 2014; NAKANO et al, 2015). Métodos de avaliação e identificação mais refinados são fundamentais para garantir o acesso aos recursos educacionais especializados a esta população, sendo necessários mais estudos sobre o tema.

A questão dos superdotados underachievement, que apresentam alto potencial cognitivo em testes padronizados e baixa performance acadêmica, foi encontrada em 3 artigos (OUROFINO; FLEITH, 2011; TENTES; FLEITH, 2014a; TENTES; FLEITH, 2014b). Ourofino e Fleith (2011) constataram que de cada dois superdotados identificados, um é considerado underachiever, o que revela uma situação alarmante, pois ocorre em nossos sistemas de ensino um desperdício e fuga de potenciais.

Os estudos de Negrini e Freitas (2013) e Cardoso e Becker (2014), tendo como sujeitos crianças surdas e meninos em situação de rua, respectivamente, merecem destaque devido a escassez de publicaçóes relacionando as AH/SD a tais condiçôes. Se a adequação do currículo escolar como uma forma de contribuir para o desenvolvimento dos indivíduos superdotados típicos já é importante, para os indivíduos superdotados e com deficiência esta adequação se torna imprescindível para que suas necessidades sejam supridas e, ao mesmo tempo, suas habilidades sejam desenvolvidas. $\mathrm{O}$ mesmo se aplica às populaçóes de risco, que podem não ter suas habilidades desenvolvidas e, consequentemente, sua realidade transformada, devido à falta de atenção dos profissionais para com este público.

Também há escassez de publicaçôes descrevendo programas visando ao desenvolvimento de talentos e habilidades, sendo encontrado somente um artigo que apresenta um programa brasileiro (DELOU, 2014). Publicaçóes desta natureza descreveriam experiências bem sucedidas, permitindo que as mesmas sejam replicadas e aprimoradas. Há, portanto, necessidade de que outras descriçôes como estas sejam realizadas, salientando as especificidades da população atendida e da cultura na qual está inserida.

\section{Considerações finais}

As publicações brasileiras do período de 2011 a 2015 no campo das AH/SD demonstram a escassez de estudos de intervenção realizados com esta população. Estes, ao levar em consideração a realidade e a cultura na qual estas pessoas estão inseridas, poderiam contribuir significativamente com avanços nesta recente área de estudo.

O debate sobre a questáo de gênero pode ser considerado um avanço neste período. Pesquisas demonstram o quanto preconceitos e estereótipos dificultam a identificação e a aceitação do talento da mulher, no entanto, é preciso que sejam desenvolvidos estudos propondo formas mais efetivas de atendimento a esta população, considerando tais especificidades. Outro avanço é o reconhecimento de estudantes superdotados underarchievers, havendo também a necessidade da continuidade de estudos sobre a temática.

A área da avaliação de indivíduos com indicadores de AH/SD ainda precisa se expandir no Brasil, havendo somente um pesquisador publicando na área. A criação 
e a adaptação de instrumentos para a nossa realidade se faz necessária para que esta população seja identificada de forma mais eficaz e, assim, possa ser encaminhada para programas especializados.

Muito se avançou neste período, no entanto, mitos e crenças sobre AH/SD ainda permeiam o imaginário de grande parte das pessoas, dificultando a identificação destes indivíduos e a oferta de suporte ao pleno desenvolvimento de seus potenciais.

\section{Referências}

ALENCAR. M. L. S. Contribuiçôes de Estudos de Caso para o Avanço do Conhecimento sobre Superdotaçấo. Psicologia Escolar e Educacional, Maringá, v. 19, n. 3, p. 427-434, set./dez. 2015.

ANTIPOFF, C. A.; CAMPOS, R. H. F. Superdotação e seus mitos. Revista Semestral da Associaçáo Brasileira de Psicologia Escolar e Educacional, São Paulo, v. 14, v. 2, p. 301-309, jul./dez. 2010.

BARBOSA, A. J. G.; ALMEIDA, L. C.; da MOTA, M. M. P. E. Leitor talentoso: produçáo científica em Educação e Psicologia. Psicologia Teoria e Prática, São Paulo, v. 14, n. 2, p. 152-163, 2012.

BARRETO, C. M. P. F.; METTRAU, M. B. Altas habilidades: uma questão escolar. Rev. bras. educ. espec, Marília, v. 17, n. 3, p. 413-426, set./dez. 2011.

BATISTA, A. L.; METTRAU, M. O portador de altas habilidades e sua inclusão na sociedade. Revista Educaçáo Especial, Santa Maria, n. 18, p. 05-12, abr. 2012.

BRASIL. Política Nacional de Educaçáo Especial na Perspectiva da Educaçáo Inclusiva. Brasília: Grupo de Trabalho da Política Nacional de Educação Especial, 2008.

CAMARGO, R. G.; FREITAS, S. N. Altas habilidades/superdotação e dificuldades de aprendizagem: um estudo relacional. Revista Roteiro, Joaçaba, v. 38, n. 1, p. 195-210, jan./jun. 2013.

CARDOSO, A. O. G.; BECKER, M. A. A. Identificando adolescentes em situação de rua com potencial para altas habilidades. Revista Brasileira de Educação Especial, Marília, v. 20, n. 4, p. 605-614, out./dez. 2014.

CHACON, M. C. M.; MARTINS, B. A. A produção acadêmico-científica do Brasil na área das altas habilidades/superdotação no período de 1987 a 2011. Revista Educaçáo Especial, Santa Maria, v. 27, n. 49, p. 353-372, maio/ago. 2014.

CHACON, M. C. M.; PAULINO, C. E. Reflexôes sobre precoces, prodígios, gênios e as altas habilidades, com base na neurociência cognitiva. Revista Educaçáo Especial, Santa Maria, v. 24, n. 40, p. 181-193, maio./ago. 2011.

CHAGAS, J. F.; FLEITH, D. S. Perfil de adolescentes talentosos e estratégias para o seu desenvolvimento. Psicologia Teoria e Pesquisa, Brasília, v. 27, n. 4, p. 385-392, dez. 2011.

CIANCA, F. S. C.; MARQUEZINE, M. C. A percepção dos coordenadores de licenciaturas da UEL sobre altas habilidades. Revista Brasileira de Educaçáo Especial, Marília, v. 20, n. 4, p. 591-604, out./dez. 2014.

DELOU, C. M. C. Educação de aluno com altas habilidades/superdotação: legislação e políticas educacionais para a inclusão. In: FLEITH, D. (Org.) A construçáo de práticas educacionais para alunos com altas habilidades/superdotaçáo. Brasília, DF: Ministério da Educação, 2007, vol. 01, p. 25-40.

DELOU, C. M. C. O Funcionamento do Programa de Atendimento a Alunos com Altas Habilida-des/Superdotaçăo (PAAAH/SD-RJ). Revista Educaçáo Especial, Santa Maria, v. 27, n. 50, p. 675-688, set./dez. 2014.

FERREIRA, J. F. C.; FLEITH, D. S. Características e dinâmica da família de adolescentes talentosos. Estudos de Psicologia, Natal, v. 17, n. 1, p. 15-23, jan./abr. 2012.

FLEITH, D. S.; ALENCAR, E. S. Desenvolvimento de talentos e altas habilidades. Sáo Paulo: Artmed, 2007.

FLEITH, D. S. (Org). Educaçáo Infantil: saberes e práticas da inclusão: altas habilidades/superdotação. 4.ed. Brasília: MEC, Secretaria de Educação Especial, 2006.

FRANÇA-FREITAS, M. L. P.; DEL PRETTE, A.; DEL PRETTE, Z. A. P. Habilidades sociais de crianças dotadas e talentosas. Estudos de Psicologia, Natal, v. 19, n. 4, p. 288-295, out./dez. 2014. 
Mariana de Freitas Pereira Pederro - Denise Rocha Belfort Arantes Brero - Raissa Viviani Silva - Angélica Maria Teodoro Cunha - Lucas Faria Gonçalves - Érico Bruno Viana

Campos - Carmen Maria Bueno Neme

FREITAS, M. F. R. L.; BARBOSA, A. J. G.. Autoeficácia e características de dotaçấo e talento: análise cientométrica. Psicologia da Educaçáo, São Paulo, n. 33, p. 77-93, dez. 2011.

FREITAS, S. N.; STOBÄUS, C. D. Olhando as altas habilidades/superdotação sob as lentes dos estudos curriculares. Revista Educaçáo Especial, Santa Maria, v. 24, n. 41, p. 483-500, set./dez. 2011.

GAMA, M. C. S. S. As Teorias de Gardner e de Sternberg na Educação de Superdotados. Revista Educaçáo Especial, Santa Maria, v. 27, n. 50, p. 665-674, set./dez. 2014.

GIL, A. C. Metodologia da pesquisa. São Paulo: Atlas, 2002.

GONÇALVES, F. C.; FLEITH, D. S. Estudo comparativo entre alunos superdotados e não-superdotados em relação à inteligência e criatividade. Psico, Porto Alegre, v. 42, n. 2, p. 263-268, abr./jun. 2011.

GUENTHER, Z. C; RONDINI, C A. Dotação, talento, habilidades: uma sondagem da conceituação pelo ideário dos educadores. Educaçáo em Revista, Belo Horizonte, v. 28, n. 1, p. 237-266, mar. 2012.

JESUS, D. M.; VIEIRA, A. B. Políticas e práticas inclusivas no ensino fundamental: das implicaçôes nacionais às locais. Educar em Revista, Curitiba, n. 41, p. 95-108, jul./set. 2011.

LAMAS, K. C. A.; BARBOSA. A. J. G. Características sociocognitivas de estudantes com dotaçáo e talento: estudo. Revista Brasileira de Orientaçáo Profissional, São Paulo, v. 16, n. 1, p. 35-48, jun. 2015.

LAMAS, K. C. A.; BARBOSA. A. J. G. Escolha e interesses profissionais de talentosos: análise cientométrica. Rev. bras. orientac. prof, São Paulo, v. 12, n. 2, p. 185-196, dez. 2011.

LINHARES, R. V.; FILHO, J. F.; METTRAU, M. B. As características dermatoglíficas de crianças e adolescentes talentosos do Instituto Rogério Steinberg do Rio de Janeiro - RJ. Psicologia Clinica, Rio de Janeiro, v. 25, n. 2, p. 153-164, jan./jun. 2013.

MARTINS, A. C. S.; ALENCAR, E. S. Características desejáveis em professores de alunos com altas habilidades/superdotaçẫo. Revista Educaçáo Especial, Santa Maria, v. 24, n. 39 p. 31-45, jan./abr. 2011.

MIRANDA, C. E. S.; COHEN, R. H. P. Psicanálise e sobredotação: pontuaçōes elementares. Estudos de Psicanalise, Belo Horizonte, v. 39, p. 29-35, jul. 2013.

MIRANDA, L. C. ALMEIDA, L. S. Da Identificação às Respostas Educativas para Alunos com Altas Habilidades: O Programa de Enriquecimento Odisseia. Revista de Psicologia da IMED, vol. 3, n. 2, p. 596- 606, 2011.

MOSQUERA, J. J.; STOBÄUS, C. D.; FREITAS, S. N. Altas Habilidades/Superdotação: abordagem ao longo da vida. Revista Educaçáo Especial, Santa Maria, v. 26, n. 46, p. 401-420, maio./ago. 2013.

NAKANO, T. C.; SIQUEIRA, L. G. G. Revisão de publicaçôes periódicas brasileiras sobre superdotação. Revista Educaçáo Especial, Santa Maria, v. 25, n. 43, p. 249-266, maio./ago. 2012.

NAKANO, T. C.; SIQUEIRA, L. G. G. Validade de conteúdo da Gifted Rating Scale (versão escolar) para a população brasileira. Avaliação Psicológica, Itatiba, v. 11, n. 1, p. 123-140, abr. 2012.

NAKANO, T. C. et al . Bateria para avaliação das altas habilidades/superdotação: análise dos itens via Teoria de Resposta ao Item. Estudos de Psicologia, Campinas, v. 32, n. 4, p. 729-741, out./dez. 2015.

NEGRINI, T.; FREITAS, S. N. O reconhecimento de alunos com altas habilidades/superdotaçâo na escola de surdos: problematizando a constituição escolar. ETD - Educaçáo Temática Digital, Campinas, v. 15, n. 3, p. 547-559, set./dez. 2013.

OLIVEIRA, C. G.; ANACHE, A. A. A identificação e o encaminhamento dos alunos com Altas Habilidades/ Superdotação em Campo Grande - MS. Revista Educaçáo Especial, Santa Maria, p. 61-84, nov. 2011.

OLIVEIRA, J. C.; BARBOSA, A. J. G. Bullying entre estudantes com e sem características de dotação e talento. Psicologia Reflexão e Crítica, Porto Alegre, v. 25, n. 4, p. 747-755, 2012.

OUROFINO, V. T. A. T.; FLEITH, D. S. A condição underachievement em superdotação: definiçẫo e características. Psicologia Teoria e Prática, Sáo Paulo, v. 13, n. 3, p. 206-222, dez. 2011.

OUROFINO, V. T. A. T.; FLEITH, D. S.; GONÇALVES, F. C. Fatores associados à baixa performance acadêmica de alunos superdotados. Psicologia em Pesquisa, Juiz de Fora, v. 5, n. 1, p. 28-38, ago. 2011.

OUROFINO, V. T. A. T.; GUIMARÃES, T. G. Características Intelectuais, Emocionais e Sociais do Aluno com Altas Habilidades/Superdotação. In: FLEITH, D. S. A Construção de Práticas Educacionais para Alunos com Altas Habilidades/Superdotaçáo. Brasília: Ministério da Educação/Secretaria de Educaçáo Especial, 2007. 
PASSOS, C. S.; BARBOSA, A. J. G. Características de superdotação em um par de gêmeos monozigóticos. Psico-USF, Itatiba, v. 16, n. 3, p. 317-326, set./dez. 2011.

PÉREZ, S. G. P. B. Mitos e crenças sobre as pessoas com altas habilidades: alguns aspectos que dificultam o seu atendimento. Revista do Centro de Educaçáo, Santa Maria, n. 22, 2003.

PÉREZ, S. G. P. B. O culto aos mitos sobre as altas habilidades/superdotaçáo?. Psicologia Argumento, Curitiba, v. 29, n. 67, p. 513-531, out./dez. 2011.

PEREZ, S. G. P. B.; FREITAS, S. N. A mulher com altas habilidades/superdotação: à procura de uma identidade. Rev. bras. educ. espec, Marília, v. 18, n. 4, p. 677-694, out./dez. 2012.

PEREZ, S. G. P. B.; FREITAS, S. N. Encaminhamentos pedagógicos com alunos com Altas Habilidades/ Superdotação na Educação Básica: o cenário Brasileiro. Educar em Revista, Curitiba, n. 41, p. 109-124, jul./ set. 2011.

PEREZ, S. G. P. B.; FREITAS, S. N. Estado do conhecimento na área de altas habilidades/ superdotação no Brasil: uma análise das últimas décadas. In: 32ª Reuniáo Anual da Anped, 2009, Caxambu. 2009. Disponível em: <http://32reuniao.anped.org.br/arquivos/trabalhos/GT15-5514--Int.pdf>. Acesso em: 29 mar. 2016.

PEREZ, S. G. P. B.; FREITAS, S. N. Políticas públicas para as Altas Habilidades/Superdotação: incluir ainda é preciso. Revista Educaçáo Especial, Santa Maria, v. 27, n. 50, p. 627-640, set./dez. 2014.

PFEIFFER, S. I.; JAROSEWICH, T. Gifted Rating Scales - Manual. San Antonio/TX: Pearson, 2003.

PFEIFFER. S. I.; WECHSLER, S. M. Liderança em jovens: uma proposta para identificaçăo e desenvolvimento da criatividade e superdotação. Estudos de Psicologia, Campinas, v. 30, n. 2, p. 219-229, abr./jun. 2013.

PRADO, R. M.; FLEITH, D. S.; GONCALVES, F. C. O desenvolvimento do talento em uma perspectiva feminina. Psicologia Ciência e Profissáo, Brasília, v. 31, n. 1, p. 134-145, 2011.

RANGNI, R. A.; COSTA, M. P. R. Altas habilidades/superdotação e deficiência: reflexôes sobre o duplo estigma. Educar em Revista, Curitiba, n. 53, p. 187-199, jul./set. 2014.

RANGNI, R. A.; COSTA, M. P. R. Altas habilidades/superdotação: entre termos e linguagens. Revista Educaçáo Especial, Santa Maria, v. 24, n. 41, p. 467-482, set./dez. 2011.

RANGNI, R. A.; COSTA, M. P. R. Indivíduos talentosos: o filme Gênio indomável como fonte de análise. Psicologia da Educaçáa, Sáo Paulo, n. 35, p. 197-213, dez. 2012.

REIS, A. P. P. Z.; GOMES, C. A. Práticas pedagógicas reprodutoras de desigualdades: a subrepresentação de meninas entre alunos superdotados. Revista Estudos Feministas, Florianópolis, v. 19, n. 2, p. 503-520, maio./ ago. 2011

RENZULLI, J. Modelo de enriquecimento para toda a escola: um plano abrangente para o desenvolvimento de talentos e superdotação. Revista Educaçăo Especial, Santa Maria, v. 27, n. 50, p. 539-562, set./dez. 2014.

RIBEIRO, W. J.; NAKANO, T. C.; PRIMI, R. Validade da estrutura fatorial de uma bateria de avaliaçáo de altas habilidades. Psico, Porto Alegre, v. 45, n. 1, pp. 100-109, jan.-mar. 2014.

TENTES V, T. A.; FLEITH, D. S. Características pessoais, familiares e escolares: estudo comparativo entre superdotados e superdotados underachievers. Avaliaçáo Psicológica, Itatiba, v. 13, n. 1, p. 77-85, abr. 2014.

TENTES V, T. A.; FLEITH, D. S. Estudantes superdotados e underachievers: prevalência, características, interesses e estilos de aprendizagem. Psico, Porto Alegre, v. 45, n. 2, p. 157-167, abr./jun. 2014.

VALLE-RIBEIRO, N.; BARBOSA, A. J. G. Características da produção sobre professores de alunos com dotação e talento. Psicologia da Educaçáo, São Paulo, n. 38, p. 101-112, jun. 2014.

VEIGA, E. C. Altas Habilidades/Superdotação e a psicopedagogia modular: avaliando potencialidades. Revista Educaçáo Especial, Santa Maria, v. 27, n. 50, p. 641-648, set./dez. 2014.

VEIGA. E. C.; GRANDE, D.; GROCHOSKI, S. As relaçôes entre o aluno com Altas Habilidades/Superdotação e o professor do Ensino Comum. Psicologia Argumento, Curitiba, v. 31, n. 72, p. 23-34, jan./mar. 2013.

VIEIRA, N. J. W. Identificação pela provisão: uma estratégia para a identificação das Altas Habilidades/Superdotação em adultos?. Revista Educaçáo Especial, Santa Maria, v. 27, n. 50, p. 699-712, set./dez. 2014.

VIEIRA, N. J. W.; SIMON, K. W. Diferenças e semelhanças na dupla necessidade educacional especial: altas habilidades/superdotação x Síndrome de Asperger. Revista Educaçáo Especial, Santa Maria, v. 25, n. 43, p. 319-332, maio./ago. 2012. 
Mariana de Freitas Pereira Pederro - Denise Rocha Belfort Arantes Brero - Raissa Viviani

Silva - Angélica Maria Teodoro Cunha - Lucas Faria Gonçalves - Érico Bruno Viana

Campos - Carmen Maria Bueno Neme

\section{Correspondência}

Érico Bruno Viana Campos - Universidade Estadual Paulista Júlio de Mesquita Filho, Faculdade de Ciências de Bauru, Departamento de Psicologia. Av. Eng. Luiz Edmundo Carrijo Coube, 14-01, Vargem Limpa. CEP: 17033360. Bauru, São Paulo, Brasil.

E-mail: marianafreitasp@gmail.com - drbarantes@gmail.com - rai.viviani@gmail.com - angel_mtc@hotmail. com-lucas@fc.unesp.br - ebcampos@fc.unesp.br - cmneme@gmail.com

Recebido em 06 de julho de 2016

Aprovado em 01 de junho de 2017 